\title{
Retraction Note: Simulation of sea surface temperature based on non-sampling error and psychological intervention of music education
}

\author{
Jingjia Zhang ${ }^{1}$
}

Published online: 3 November 2021

(c) Saudi Society for Geosciences 2021

Retraction Note to: Arabian Journal of Geosciences (2021) 14: 1518 https://doi.org/10.1007/s12517-021-07931-5

The Editor-in-Chief and the Publisher have retracted this article because the content of this article is nonsensical. The peer review process was not carried out in accordance with the Publisher's peer review policy. The author has not responded to correspondence regarding this retraction.

The original article can be found online at https://doi.org/10.1007/ s12517-021-07931-5.

Jingjia Zhang

ZJJ201920192019@163.com

1 School of Music and Dance, Fuyang Normal University, Fuyang, China 